\title{
Expert witnesses and areas of expertise
}

James SP Chiu *, FHKAM (Surgery), LLB (Hons) Lond, Gilberto KK Leung, FHKAM (Surgery), LLM

Professionalism and Ethics Committee, Hong Kong Academy of Medicine

*Corresponding author: drjameschiu@yahoo.com.hk

Hong Kong Med J 2022;28:4-5

https://doi.org/10.12809/hkmj215125

Expert witnesses play important roles in medicolegal and disciplinary proceedings through the provision of opinions that are within their respective areas of expertise. Contentions may occasionally arise concerning the expertise of an individual witness and whether the scope of his expertise has been exceeded in certain situations.

\section{Defining specialists and experts}

The terms "specialist" and "expert" are often used interchangeably but they may carry different meanings in the case of professionals. In 1998, the Medical Council of Hong Kong established a Specialist Register to provide for specialist registration of medical practitioners who have been awarded Fellowships of the Hong Kong Academy of Medicine or who have achieved a comparable professional standard and have applied to the Medical Council of Hong Kong for specialist registration. ${ }^{1}$ By contrast, there is no official list of medical experts in Hong Kong and the term "expert" is not defined in Cap. 1 Interpretation and General Clauses Ordinance or Cap. 4A The Rules of the High Court. The Hong Kong Academy of Medicine maintains a list of Academy Fellows who are willing to serve as expert witnesses in their respective specialties. However, disputing parties and their legal advisers may freely engage any registered doctor or dentist of their choice to be their expert witness, whether the individual is on the Academy's list or not.

\section{Duties and responsibilities of expert witnesses in relation to their expertise}

In the landmark case of The Ikarian Reefer, ${ }^{2}$ the court set out the duties and responsibilities of expert witnesses in civil cases, two of which are related to expertise. First, an expert witness should provide independent assistance to the Court by way of objective unbiased opinion in relation to matters within his expertise. Second, an expert witness should make it clear when a particular question or issue falls outside his expertise. Similarly, the Code of Conduct for Expert Witnesses ${ }^{3}$ provides that an expert witness has an overriding duty to help the Court impartially and independently on matters relevant to the expert's area of expertise. A report by an expert witness must (in the body of the report or in an annexure) specify, if applicable, that a particular question or issue falls outside his field of expertise. In Zahid Anwar v Graceful Sound Limited, ${ }^{4}$ Bharwaney J stated that, "Experts are instructed to assist the court by offering their expert opinion on areas which are within their specialist experience and which are not matters of common knowledge".

\section{Matters relating to an expert witness' areas of expertise}

Medicine has evolved to include many specialties under which there are multiple subspecialties. Professional expertise is accumulated from years of studying, training, and personal experience in a specific area of medicine. It follows that not all specialists are competent expert witnesses. A specialist in Gastroenterology and Hepatology may not act as an expert witness for a case concerning endoscopic retrograde cholangiopancreatography, sphincterotomy, and extraction of common bile duct stones if he does not have substantial knowledge and practical experience in these procedures.

In a recent Hong Kong case, the expert witness for the defendants was a specialist in paediatrics, and that for the plaintiffs was a specialist in paediatric surgery. The court acknowledged that the relevant standard to be applied under the Bolam test on the issue of liability for medical negligence was whether the defendant (who was a paediatrician) had acted in accordance with the practice accepted as proper by a responsible body of "medical men skilled in that particular art", which particular art was that of paediatric specialists and not that of paediatric surgery specialists. ${ }^{5}$ The boundary becomes less clear when a specialist in general surgery is asked to comment on an orthopaedic case. It may be proper for him to comment on general principles of postoperative care but not detailed surgical techniques in orthopaedics. The situation is even more challenging when the case involves several body systems and multidisciplinary care. Medical and dental practitioners invited to be expert witnesses should be mindful of any limitations of their areas of expertise in relation to the medicolegal issue at hand and to act within those boundaries as a matter of duty to the court and professional respect towards their peers who possess the relevant specialised skills and 
knowledge. In cases involving matters of multiple areas of expertise, the practitioner may suggest the parties to invite suitable experts of other specialties or subspecialties to be witnesses, if necessary.

Medical and dental practitioners appointed to give evidence in courts, tribunals, or inquests are advised to: consider seeking legal advice; provide answers truthfully based on their personal knowledge and beliefs; avoid making up answers; avoid answering questions that are beyond their scope of practice; and exercise the right to refuse to answer questions that could result in self-incrimination. ${ }^{6}$

\section{Potential consequences of giving mistaken evidence}

Misleading or "manifestly wrong" expert evidence can have untoward and far-reaching consequences. The professional or academic status of an expert witness by itself offers no excuses. In the United Kingdom case of $R v$ Sally Clark, $^{7}$ a prosecution expert witness was Professor Sir Roy Meadow, an Emeritus Professor of Paediatrics and Child Health. Evidence relating to statistics were given by the professor, who did not disclose his lack of expertise in statistics. Mrs Clark was convicted of the murder of her two sons and received two life sentences in 1999. Her appeal was dismissed. It later transpired that Professor Meadow made one mistake, which was to misunderstand and misinterpret the statistics. Mrs Clark made a second appeal and was set free in 2003. Her father then made a complaint to the General Medical Council (GMC) alleging serious professional misconduct on the part of Professor Meadow. In 2005, the GMC found him guilty, and his name was erased from the register. He appealed to the High Court and the order of the GMC was quashed. The GMC appealed to the Court of Appeal in 2006. ${ }^{8}$ There were two distinct parts of the appeal. The first was whether an expert witness should be entitled to immunity from disciplinary, regulatory or fitness to practise proceedings in relation to statements made or evidence given by him in or for the purpose of legal proceedings. The second entailed a consideration of the GMC's challenge to the High Court judge's decision that Professor Meadow was not guilty of serious professional misconduct. The Court of Appeal allowed the first part of the appeal and held that the Fitness to Practice Panel of the GMC had jurisdiction to entertain the allegations against Professor Meadow. However, the second part of GMC's appeal on the issue of 'serious professional misconduct' was rejected.

\section{Training for expert witnesses}

Specialists do not automatically make good expert witnesses. It is advisable for anyone interested to take up this job to undergo formal training first. Start with simple cases and work closely with instructing lawyers to gain experience and accumulate the necessary skills. Otherwise, it can result in unpleasant experience if he has to appear in courts or tribunals and may even become a defendant himself or cause irreversible harm to the parties.

\section{Author contributions}

Both authors contributed to the editorial, approved the final version for publication, and take responsibility for its accuracy and integrity.

\section{Conflicts of interest}

The authors have declared no conflict of interest.

\section{References}

1. The Medical Council of Hong Kong. Available from: https://www.mchk.org.hk/english/registration/specialist_ registration.html. Accessed 25 Nov 2021.

2. The Ikarian Reefer [1993] Lloyd's Rep 68, pp 81-82.

3. Cap. 4A, The Rules of the High Court, Appendix D.

4. Zahid Anwar v Graceful Sound Limited \& Ors HCPI 410/2008 \& HCPI 370/2009

5. Sun Ming Lok $v$ Choy Wing Ho \& St Teresa's Hospital HCPI 200/2017

6. Tsang C, Lee V. Coroner's inquest-What do you need to know? Hong Kong Medical Association News, October 2021: 23.

7. $R v$ Sally Clark [2003] EWCA Crim 1020

8. GMC v Professor Sir Roy Meadow [2006] EWCA Civ 1390 